\title{
Vasoactive and atherogenic effects of cigarette smoking: a study of monozygotic twins discordant for smoking
}

\author{
R Lassila, H W Seyberth, A Haapanen, H Schweer, M Koskenvuo, K E Laustiola
}

\begin{abstract}
The mechanism by which atherosclerotic disease is induced by cigarette smoking has not yet been identified unequivocally. Chronic cigarette smoking and the generation of vasoactive prostanoids and the size of carotid atherosclerotic plaques were studied in nine pairs of identical male twins discordant for smoking for over 20 years. The urinary excretion of 2,3-dinor-thromboxane $B_{2}$ (thromboxane $B_{2}$ metabolite) of the smoking twin was significantly higher (on average 1.8 times higher) in every pair and that of 2,3-dinor-6-ketoprostaglandin $F_{1 \alpha}$ (prostacyclin metabolite) was significantly higher (on average 1.3 times higher) in eight of the nine pairs. The ratio of excretion of these metabolites was significantly higher, being $4.0(95 \%$ confidence interval 2.7 to 5.4$)$ among the smokers compared with $2.9(2 \cdot 1$ to 3.8$)$ among the non-smokers, thus favouring a mechanism of vasoconstriction. Excretion of the thromboxane $B_{2}$ metabolite was related to the urinary concentrations of nicotine metabolites. Atherosclerotic plaques detected by ultrasonography in the carotid arteries were significantly larger among smokers but did not correlate with the urinary excretion of prostacyclin and thromboxane $B_{2}$ metabolites or intensity of smoking.

Smoking was concluded to induce activation of platelets by an effect mediated by nicotine. The increased prostacyclin production, on the other hand, suggested a compensatory mechanism for the general vasoconstrictive properties of cigarette smoking.
\end{abstract}

\section{Introduction}

Although cigarette smoking is strongly and consistently correlated with the increased incidence of atherosclerotic disease, little information is available about how it exerts its cardiovascular effects. ${ }^{.}$Postmortem examinations have shown that atherosclerotic lesions are significantly more common in cigarette smokers than non-smokers in the aorta and iliac and cerebral arteries but not consistently so in coronary arteries. ${ }^{23}$ Studies in animals have suggested that cigarette smoking damages the arterial wall by hypoxia and antigenic mechanisms. ${ }^{45}$ Nicotine alone carries structural changes in aortic endothelial cells and their intercellular connections, suggesting that their permeability to nicotine is increased. ${ }^{6}$

Smoking is thrombogenic, increasing the risk of complications of atherosclerotic disease, in which arterial thrombosis has an important role. ${ }^{7-9}$ The results of studies of dysfunction or hyperreactivity of platelets induced by smoking have not been consistent. ${ }^{111}$ On the other hand, activation of platelets has been thought to contribute to the genesis of vascular occlusive disease by its role in thrombosis as well as atherogenesis. ${ }^{1213}$

Smoking also has vasoconstrictive properties, ${ }^{14}$ and the effect of the dynamics of the flow of blood locally interacts in atherogenesis and thrombogenesis. ${ }^{15}{ }^{16}$ According to current knowledge, thromboxane $\mathrm{A}_{2}$, which is the main product of the action of cyclooxygenase on arachidonic acid in platelets, acts as a potent vasoconstrictor, and excessive excretion of its metabolites may reflect activation of platelets in vivo. Prostacyclin (prostaglandin $\mathrm{I}_{2}$ ), a potent vasodilator, is the predominant product of the same cyclo-oxygenase in vascular endothelial cells and inhibits aggregation of platelets in vitro. The excretion of 2,3-dinormetabolites of vasoactive prostanoids (thromboxane $B_{2}$ derived from platelets and prostacyclin from the vascular endothelium) is thought to reflect the degree of their release locally into the circulation..$^{17} 18$

The aim of the present study was to evaluate the effects of chronic cigarette smoking on the urinary excretion of these vasoactive prostanoids in monozygotic twins who had been discordant for smoking for over 20 years. As atherosclerotic changes influence the concentrations of these vasoactive prostanoids ${ }^{18}$ the grade of atherosclerotic plaques was also assessed.

\section{Subjects and methods}

We enrolled nine pairs of monozygotic male twins who were discordant for smoking from the Finnish twin cohort, which collected documents of zygosity and history of lifestyle and socioeconomic state by questionnaires in 1975, 1981, and $1986 .{ }^{19}$ All the subjects were healthy except one of the smokers, who had undergone a vascular reconstruction for peripheral arterial disease two years before; none was receiving any regular treatment. Their mean age was $\mathbf{4 0}$ (range 31-53). Discordance for smoking had lasted on average 22 (range 12-35) years, and mean cigarette consumption among the smokers was 18 (range 5-39) cigarettes daily. The non-smokers had never smoked regularly. To measure the lifelong dose of smoking we calculated so called pack years (which corresponded to smoking one packet of cigarettes daily for a year). We used the colorimetric method of Peach et al to measure urinary concentration of nicotine metabolites ${ }^{20}$ to confirm the subjects as smokers or non-smokers. The weight and height of each pair of twins were not significantly different, nor were serum concentrations of total cholesterol and low density lipoprotein and high density lipoprotein cholesterol, creatinine clearance, and plasma sodium, potassium, and glucose concentrations, all of which were within normal limits. The mean heart rate of the smokers at rest was slightly higher, but blood pressures did not differ.

The subjects were asked not to take any medicines, especially anti-inflammatory drugs, for two weeks before the study, and alcohol was not permitted for 48 hours before urine was collected. Urine was collected over 12 hours from 2000 to 0800 , from which the urinary excretion of cotinine, the prostacyclin metabolite 2,3-dinor-6-keto-prostaglandin $\mathrm{F}_{1 \alpha}$, and the thromboxane $\mathrm{B}_{2}$ metabolite 2,3-dinor-thromboxane $\mathrm{B}_{2}$ were measured. The results were calculated as absolute values $(\mathrm{ng} / \mathrm{h})$ and also corrected for creatinine excretion ( $\mathrm{pg} / \mathrm{mg}$ creatinine). Originally 10 pairs of twins were suitable for the study, but one pair had to be excluded as they failed to follow the given instructions when preparing for the study.

The thromboxane $B_{2}$ metabolite was determined by spiking $5 \mathrm{ml}$ of urine with deuterium labelled metabolite at positions 19 and 20 , conversion to the methoxime derivative, and extraction on a phenylboronic acid column. The eluate was evaporated to about $1 \mathrm{ml}$ on a rotary evaporator and the
Correspondence to: Dr Laustiola. 
thromboxane derivative alkylated to the pentafluorobenzyl ester during extraction with $1 \mathrm{ml}$ neutral solution of tetrabutylammonium hydrogen sulphate ( $10 \mathrm{mg} / \mathrm{ml}$, adjusted to $\mathrm{pH} 7$ with sodium hydroxide), $10 \mu \mathrm{l}$ pentafluorobenzylbromide, and $3 \mathrm{ml}$ dichloromethane. The sample was purified by thin layer chromatography, converted to the trimethylsilylether derivative with bis(trimethylsilyl)trifluoroacetylacetamide, and analysed by gas chromatography-negative ion chemical ionisation mass spectrometry. ${ }^{21}$ The prostacyclin metabolite was also assessed by this type of spectrometry. ${ }^{22}$

Atherosclerotic changes of bifurcations of the carotid were assessed by duplex Doppler ultrasonography of the carotid arteries of each subject ${ }^{23}$ by a radiologist who did not know which twin was a smoker. An echogenic area was called a plaque if the stenosis it caused was less than $15 \%$ of the vessel lumen, otherwise it was termed a stenosis. Breadth and height of the plaques were measured from the transverse section of the ultrasound image of the carotid bifurcation to obtain the transverse area of the plaque.

Statistics-The results in both groups were compared in pairs by determining the $95 \%$ confidence intervals for the mean paired differences. Correlation coefficients were calculated to disclose the interrelations between the results in the non-smokers and smokers. Proportional differences were analysed by a paired two tailed $t$ test.

\section{Results}

Among smokers the number of mean pack years was $14 \cdot 7$ (range $5 \cdot 2-33 \cdot 6$ ); the correlation between reported daily smoking and urinary cotinine concentration was not significant $(r=0 \cdot 44)$. Socioeconomic state and lifestyle were not appreciably different between the smokers and non-smokers, particularly in terms of exercise habits and consumption of alcohol or coffee. Urinary excretion of the thromboxane $\mathrm{B}_{2}$ metabolite was significantly higher among all nine of the smokers compared with their non-smoking twins, and that of the prostacyclin metabolite was significantly higher in eight of the smokers $(p<0.01)$, whether the results were corrected for creatinine excretion or presented as absolute excretion/hour. The ratio of excreted thromboxane $B_{2}$ metabolite to prostacyclin metabolite was

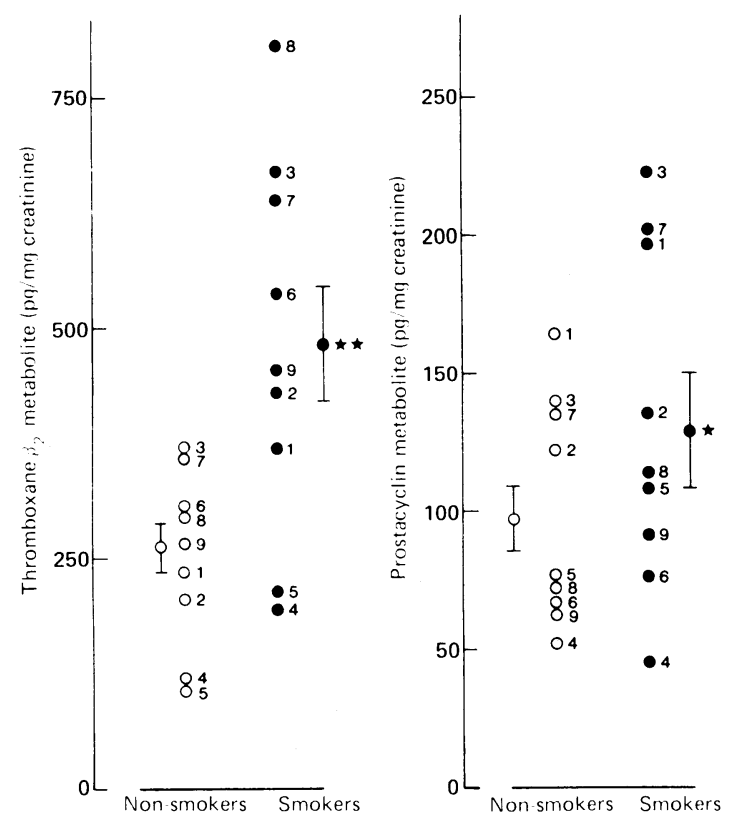

Urinary excretion of thromboxane $B_{2}$ and prostacyclin metabolites corrected for creatinine excretion in non-smoking $(\bigcirc)$ and smoking $(\bigcirc)$ monozygotic twins (numbered) significantly higher among eight of the smokers (ratio $4.0(95 \%$ confidence interval $2 \cdot 7$ to $5 \cdot 4)$ among smokers $v 2.9(95 \%$ confidence interval 2.1 to 3.8$)$ among non-smokers; $p<0 \cdot 005)$. The figure shows the individual results and the table the mean values.

Mean urinary cotinine concentration, excretion of prostacyclin and thromboxane $B_{2}$ metabolites, and area of atherosclerotic plaques at carotid bifurcation in monozygotic twins discordant for smoking

\begin{tabular}{|c|c|c|c|}
\hline & $\begin{array}{l}\text { Non- } \\
\text { smoking } \\
\text { twin }\end{array}$ & $\underset{\text { twin }}{\text { Smoking }}$ & $\begin{array}{c}\text { Mean paired } \\
\text { difference }(95 \% \\
\text { confidence interval) }\end{array}$ \\
\hline Cotinine $(\mathrm{mg} / \mathrm{l})$ & $0 \cdot 1$ & $1 \cdot 4$ & $1.4 \quad(0.5$ to 2.2$)$ \\
\hline $\begin{array}{l}\text { Prostacyclin metabolite } \\
\text { ( } \mu \mathrm{g} / \mathrm{g} \text { creatinine })\end{array}$ & $99 \cdot 7$ & $131 \cdot 7$ & $21.9(10 \cdot 1$ to 53.9$)$ \\
\hline Prostacyclin metabolite $(\mathrm{ng} / \mathrm{h})$ & 5.9 & $7 \cdot 6$ & $1.7(0.1$ to 3.4$)$ \\
\hline $\begin{array}{l}\text { Thromboxane metabolite } \\
\text { ( } \mu \mathrm{g} / \mathrm{g} \text { creatinine) }\end{array}$ & $263 \cdot 2$ & 479.9 & $216 \cdot 7(107 \cdot 0$ to $326 \cdot 4)$ \\
\hline $\begin{array}{l}\text { Thromboxane metabolite } \\
(\text { ng/h) } \\
\text { Plaque area }\left(\mathrm{mm}^{2}\right)\end{array}$ & $\begin{array}{r}16 \cdot 1 \\
1.9\end{array}$ & $\begin{array}{r}27 \cdot 9 \\
6 \cdot 5\end{array}$ & $\begin{aligned} 11.7 & (4.7 \text { to } 18.7) \\
4.6 & (0.9 \text { to } 8.3)\end{aligned}$ \\
\hline
\end{tabular}

Changes indicative of atherosclerosis - that is, the areas of echogenic plaques of the carotid arterieswere greater in the smokers. The one smoker who had peripheral arterial disease had the most pronounced lesion of all, a stenosis of $19 \%$ in the carotid area. No other subject had any detectable stenosis. The interrelation among the vasoactive metabolites of thromboxane $\mathrm{B}_{2}$ and prostacyclin, the areas of atherosclerotic plaques, and the intensity of smoking showed significant correlations between urinary concentrations of the thromboxane $B_{2}$ metabolite and long term smoking as measured in pack years $(\mathrm{r}=0.83, \mathrm{p}<0.01)$ as well as short term smoking as measured by urinary cotinine excretion $(r=0.67, p<0.05)$; all other correlations were non-significant.

\section{Discussion}

The subjects, monozygotic pairs of male twins whose only apparent discordant factor was smoking, offered a unique opportunity to evaluate the effects of smoking on cardiovascular pathogenesis. As the genetic effects are controlled for, differences in metabolism in each pair can be interpreted as being due to cigarette smoking. The discrepancy noted between the reported number of cigarettes smoked daily and cotinine concentration could have two possible explanations: subjective reports of smoking are unreliable,${ }^{24}$ and the constituents of tobacco smoke are inhaled and absorbed differently in different people. ${ }^{25}$ This may cause bias in epidemiological studies, which evaluate the effects of amount of smoking based only on subjective reports.

Our results show that excretion of the thromboxane $\mathrm{B}_{2}$ metabolite is increased significantly in chronic cigarette smokers, confirming earlier findings. ${ }^{26-28}$ The same method was used in our study - that is, measurement of a dinor metabolite from urine-which suggests extrarenal formation of thromboxane in vivo, derived largely from platelets under certain physical conditions. ${ }^{17}$ Nowak et al, treating subjects with low dose aspirin, showed that platelets are the predominant source of the increase of this metabolite induced by smoking. ${ }^{27}$ The fact that among smokers the concentration of the thromboxane $B_{2}$ metabolite and the intensity of smoking were highly correlated suggests a direct influence of smoking on platelets. This is also supported by a decline in the thromboxane $B_{2}$ metabolite as early as one week after smoking was stopped and an increase again after it was restarted. ${ }^{26}$ Also the excretion of the prostacyclin metabolite was enhanced in the twins who smoked. Aortic tissue of rats exposed to cigarette smoke in vitro has, however, a reduced ability to generate prostacyclin..$^{29}$ 
Similarly, nicotine inhibits prostacyclin synthesis by venous tissue in humans. ${ }^{30}$ Our results, which agree with those of Nowak et al, ${ }^{27}$ do not necessarily conflict with these experiments, in which the ability to generate prostacyclin has been measured in response to strong direct stimuli in vitro as this does not relate to the actual rates of production in vivo. ${ }^{18}$

The degree to which excretion of the thromboxane $B_{2}$ metabolite in proportion to that of the prostacyclin metabolite was raised may point to an additional vasoconstrictive load for smokers, among whom sympathoadrenergic activation already suggests enhanced vasoconstriction. ${ }^{31-33}$ Release of prostacyclin to compensate for vasoconstriction has been shown with sympathoadrenergic and neurohormonal activation. In humans vasoconstriction mediated by prostaglandin $F_{1 \alpha}$ receptor releases urinary prostaglandins in response to infusion with norepinephrine, ${ }^{34}$ and in an animal model stimulation of the sympathetic nerves leads to a significant rapid increase in output of prostacyclin from the mesenteric arterial bed. ${ }^{35}$ The importance of vasodilatory prostaglandins in maintaining circulatory homoeostasis is evident in congestive heart failure, in which plasma concentrations of prostaglandin $I_{2}$ and prostaglandin $E_{2}$ metabolites correlate with the degree of activation of the neurohumoral vasoconstrictor systems. ${ }^{36}$

Although cigarette smoking is closely associated with peripheral arterial disease and atherosclerosis occurs first in the abdominal and iliac aortas, we assessed the grade of atherosclerosis in the carotid arteries owing to easier access in the neck and the limitations of ultrasonography in accurately detecting the state of arteries in the legs. Prostacyclin biosynthesis is appreciably increased in patients with severe atherosclerosis and activation of platelets. ${ }^{18}$ In this study the smokers had more pronounced atherosclerotic changes than the non-smokers, but the changes were not severe enough to cause clinical manifestations and were not associated with the excretion of prostacyclin and thromboxane metabolites. Thus the finding of high urinary concentrations of the prostaglandin and thromboxane $\mathrm{B}_{2}$ metabolites suggests that cigarette smoking can cause release of excessive vasoactive prostanoids to the circulation.

In conclusion, the study shows that chronic cigarette smoking can enhance the progression of atherosclerotic lesions in carotid bifurcations even without hyperlipidaemia. The increased excretion of the main metabolites of vasoactive prostanoids among smokers points to a dysfunction of both vascular walls and platelets. We have thus confirmed earlier findings ${ }^{27}$ by studying pairs of subjects who are genetically identical. The urinary concentrations of the thromboxane $B_{2}$ metabolite were closely associated with the intensity of smoking, thus implying direct effects of smoking tobacco on activation of platelets. The increased biosynthesis of thromboxane $A_{2}$ additionally enhances the other vasoconstrictive properties of smoking. As prostacyclin is known to be a reactive vasodilator in regulating the circulation under various circumstances we propose that it compensates for the profound vasoconstrictive effects of cigarette smoking.

We thank Karin Soeding and Simone Gund for their technical help, and Drs Udo Axen and John Pike (Upjohn, Kalamazoo, Michigan, United States) for providing the unlabelled and deuterated prostanoids. The study was partly supported by grants from the Meilahti Foundation Helsinki, Finland; the Council for Tobacco Research, United States; and Deutsche Forschungsgemeinschaft. HWS is a Hermann and Lilly Schilling professor of medical research.

1 Ross R. Pathophysiology of atherosclerosis. In: Wilson SE, Veith FJ, Hobson RW, Williams RA, eds. Vascular surgery: principles and practice. New York: McGraw-Hill, 1987:11-22.
2 Strong JP, Richards ML. Cigarette smoking and atherosclerosis in autopsied men. Atherosclerosis 1976;23:451-76.

3 Sternby NH. Atherosclerosis, smoking and other risk factors. In: Gotto AM Jr, Smith LC, Allen B, eds. Atherosclerosis. Vol 5. New York: SpringerVerlag, 1979:67-70

4 Kjeldsen K, Wanstrup J, Astrup P. Enhanced influence of arterial hypoxia on the development of atherosclerosis in cholesterol-fed rabbits. $\mathcal{F}$ Atheroscler Res 1968;8:835-45.

5 Becker CG, Dubin T, Wiedemann HP. Hypersensitivity to tobacco antigen. Proc Natl Acad Sci USA 1976;73:1712-6.

6 Zimmerman $M, M c G e a c h e J$. The effect of nicotine on aortic endothelium - a quantitative ultrastructural study. Atherosclerosis 1987;63:33-41.

7 Hallstrom AP, Cobb LA, Ray R. Smoking as a risk factor for recurrence of sudden cardiac arrest. N Englf Med 1986;314:271-5.

8 Abbott RD, Yin Y, Reed DM, Yano K. Risk of stroke in male cigarette smokers. N Engl f Med 1986;315:717-20.

9 Hughson WG, Mann JI, Tibbs DJ, Woods HF, Walton I. Intermitten claudication: factors determining outcome. Br Med f 1978;i:1377-9.

10 Schmidt KG, Rasmussen JW. Acute platelet activation induced by smoking. In vivo and ex vivo studies in humans. Thromb Haemost 1984;51:279-82.

11 Davis JW, Lewis HD, Phillips PE, Davis RF. Relationship of the platelet aggregate ratio to serum cholesterol concentration, smoking and age Postgrad Med f 1981;57:150-2.

12 Packham MA, Mustard JF. The role of platelets in the development and complications of atherosclerosis. Semin Hematol 1986;23:8-26.

13 Bowen-Pope DF, Vogel A, Ross R. Production of platelet-derived growth factor-like molecules and reduced expression of platelet-derived growth factor receptors accompany transformation by a wide spectrum of agents. Proc Natl Acad Sci USA 1984;81:2396-400.

14 Winniford MD, Jansen DE, Reynolds GA, et al. Cigarette smoking-induced coronary vasoconstriction in atherosclerotic coronary artery disease and prevention by calcium antagonists and nitroglycerin. Am J Cardiol 1987;59: 203-7.

15 Nerem RM, Murina J, Levesque J. Hemodynamics and arterial wall. In: Strandness, DE Jr, Didisheim P, Clowes AW, Watson JT, eds. Vascular diseases-current research and clinical applications. Orlando: Grune and Siseases-current research

16 Baumgartner HR, Sakariassen KS. Factors controlling thrombus formation on arterial lesions. Ann NY Acad Sci 1985;454:162-77.

17 FitzGerald GA, Pedersen AK, Patrono C. Analysis of prostacyclin and thromboxane biosynthesis in cardiovascular disease. Circulation 1983;67 $1174-7$

18 FitzGerald GA, Smith B, Pedersen AK, Brash AR. Increased prostacyclin biosynthesis in patients with severe atherosclerosis and platelet activation. N Engl F Med 1984;310:1065-8.

19 Kaprio J, Sarna S, Koskenvuo M, Rantasalo I. The Finnish Twin Registry formation and compilation, questionnaire study, zygosity determination procedures and research program. Prog Clin Biol Res 1978;24B:179-84.

20 Peach H, Ellard GA, Jenner PJ, Morris RW. A simple, inexpensive urine tes for smoking. Thorax 1985;40:351-7.

21 Lawson JA, Brash AR, Doran J, FitzGerald GA. Measurement of urinary 2,3-dinor-thromboxane $B_{2}$ using bonded-phase phenylboronic acid columns 2,3-dinor-thromboxane $B_{2}$ using bonded-phase phenylboronic acid columns
and capillary gas chromatography-negative-ion chemical ionization mass and capillary gas chromatography-negative-i
spectrometry. Anal Biochem 1985;150:463-70.

22 Falardeau P, Oates JA, Brash AR. Quantitative analysis of two dinor urinary metabolites of prostaglandin $I_{2}$. Anal Biochem 1981;115:359-67.

23 Jackson VP, Bendick PJ. Duplex ultrasound screening for carotid arteriosclerotic disease in asymptomatic patients. F Ultrasound Med 1985;4:411-5.

$24 \mathrm{McMahan}$ CA, Richards ML, Strong JP. Individual cigarette usage. Self reported data as a function of respondent-reported data. Atherosclerosis 1976;23:477-88.

25 Jarvik ME. Biological factors underlying the smoking habit. In: Jarvik ME Cullen JW, Gritz ER, Vogt TM, West LJ, eds. Research on smoking behaviour. Maryland: National Institute on Drug Abuse, 1977:122-46. (Research Monograph Series 17.)

26 Murray JJ, Nowak J, Oates JA, FitzGerald GA. Biosynthesis of thromboxane $\mathrm{A}_{2}$ and prostacyclin during chronic cigarette smoking and withdrawal in man [Abstract]. Clin Res 1985;33:512a.

27 Nowak J, Murray JJ, Oates JA, FitzGerald GA. Biochemical evidence of chronic abnormality in platelet and vascular function in healthy individuals who smoke cigarettes. Circulation 1987;76:6-14.

28 Fischer J, Bernutz C, Meier H, Weber PC. Formation of prostacyclin and thromboxane in man as measured by the main urinary metabolites. Biochim Biophys Acta 1986;876:194-8.

29 Pittilo RM, Mackie IJ, Rowles PM, Machin SJ, Woolf N. Effects of cigarette smoking on the ultrastructure of rat thoracic aorta and its ability to produce prostacyclin. Thromb Haemost 1982;48:173-6.

30 Sonnenfeld T, Wennmalm $\AA$. Inhibition by nicotine of the formation of prostacyclin-like activity in rabbit and human vascular tissue. $\mathrm{Br} f$ Pharmacol 1980;71:609-13.

31 Klein LW, Ambrose J, Pichard A, et al. Acute coronary hemodynamic response to cigarette smoking in patients with coronary disease. $7 \mathrm{Am} \mathrm{Coll}$ Cardiol 1984;3:879-86.

32 Caro CG, Lever MJ, Parker KH, Fish PJ. Effect of cigarette smoking on the pattern of arterial blood flow: possible insights into mechanisms underlying the development of arteriosclerosis. Lancet 1987;ii:11-3.

33 Cryer PE, Haymond MW, Santiago JV, Shah SD. Norepinephrine and epinephrine release and adrenergic mediation of smoking-associated hemodynamic and metabolic events. N Engl f Med 1976;295:573-7.

34 Nadler J, Zipser RD, Horton R. The effect of adrenergic stimulation on urinary prostaglandin $\mathrm{E}_{2}$ and 6-keto- $\mathrm{PGF}_{1}$ in man. Prostaglandins 1983;26: 519-30.

35 Pipili E, Poyser NL. Release of prostaglandins $I_{2}$ and $E_{2}$ from the perfused mesenteric arterial bed of normotensive and hypertensive rats. Effects of sympathetic nerve stimulation and norepinephrine administration. Prostaglandins 1982;23:543-9.

36 Dzau VJ, Packer M, Lilly LS, et al. Prostaglandins in severe congestive heart failure. Relation to activation of the renin-angiotensin system and hyponatremia. N Engl f Med 1984;310:347-52.

(Accepted 9 fune 1988) 